American Journal of Pharmaceutical Education 2016; 80 (9) Article 149.

\title{
RESEARCH
}

\section{Evaluation of a Teaching Assistant Program for Third-Year Pharmacy Students}

\author{
Courtney L. Bradley, PharmD, BCACP, ${ }^{a}$ Julia Khanova, PhD, ${ }^{b}$ Kelly L. Scolaro, PharmD ${ }^{c}$ \\ ${ }^{\text {a }}$ Fred Wilson School of Pharmacy, High Point University, High Point, North Carolina \\ ${ }^{\mathrm{b}}$ School of Information and Library Science, The University of North Carolina at Chapel Hill, North Carolina \\ ${ }^{\mathrm{c}}$ LECOM Bradenton School of Pharmacy, Bradenton, Florida
}

Submitted August 14, 2015; accepted November 4, 2015; published November 25, 2016.

Objectives. To determine if a teaching assistant (TA) program for third-year pharmacy students (PY3s) improves confidence in teaching abilities. Additionally, 3 assessment methods (faculty, student, and TA self-evaluations) were compared for similarities and correlations.

Methods. An application and interview process was used to select 21 pharmacy students to serve as TAs for the Pharmaceutical Care Laboratory course for 2 semesters. Participants' self-perceived confidence in teaching abilities was assessed at the start, midpoint, and conclusion of the program. The relationships between the scores were analyzed using 3 assessment methods.

Results. All 21 TAs agreed to participate in the study and completed the 2 teaching semesters. The TAs confidence in overall teaching abilities increased significantly ( 80.7 vs $91.4, p<0.001)$. There was a significant difference between the three assessment scores in the fall $(p=0.027)$ and spring $(p<0.001)$ semesters. However, no correlation was found among the assessment scores.

Conclusions. The TA program was effective in improving confidence in teaching abilities. The lack of correlation among the assessment methods highlights the importance of various forms of feedback.

Keywords: teaching assistants, teaching evaluations, skills lab, pharmacy education

\section{INTRODUCTION}

The need for new faculty members at colleges and schools of pharmacy has increased significantly in the last 4 years. ${ }^{1,2}$ There are several contributing factors for this including the substantial increase in the number of new pharmacy schools and colleges and the retirement of hundreds of faculty members. With the increased need for new faculty members, there is clearly a need for schools to provide appropriate training and recruitment of academicians. One way this could be accomplished is by identifying academic career interest among pharmacy students and residents.

There are many pharmacy residency programs that prepare residents for academia, especially through teaching

Corresponding Author: Courtney L Bradley, Fred Wilson School of Pharmacy, High Point University, One University Parkway, High Point, North Carolina 27268. Tel: 336-8419715. Fax: 336-888-6394. E-mail: cbradley@highpoint.edu Note: At the time the study was conducted, Courtney Bradley was an academic postdoctoral fellow, Julia Khanova was a post-doctoral research associate, and Kelly Scolaro was a Clinical Assistant Professor at the UNC Eshelman School of Pharmacy, The University of North Carolina at Chapel Hill, North Carolina certificate programs. ${ }^{3-12}$ However, only a few publications have examined program outcomes related specifically to pharmacy student teaching. Some opportunities offered by institutions to stimulate pharmacy student knowledge and interest in academia include teaching electives and advanced pharmacy practice experiences (APPEs). ${ }^{13-16}$ Nonetheless, additional educational opportunities are needed to encourage students to consider a career in academic pharmacy. Student teaching programs may meet the goal of furthering student knowledge of academic pharmacy.

While there is limited evidence that suggests student teaching in pharmacy leads to increased interest in academia, there is some evidence from other educational settings, such as peer tutoring programs within health professions schools, which generally showed a positive benefit. ${ }^{17}$ Other documented successes occurred with teaching assistant (TA) programs in undergraduate and nursing education, with positive feedback received from students. ${ }^{18,19}$ In another study in which dental students were employed as educators, no difference was seen between the education provided by senior students and that provided by faculty members. ${ }^{20}$ Finally, there is a report of a nutrition elective taught by a pharmacy student who was also a registered dietician. ${ }^{21}$ 


\section{American Journal of Pharmaceutical Education 2016; 80 (9) Article 149.}

One additional consideration is the use of formal faculty development programs to train students interested in academic careers. Two publications describe faculty development programs within a dental school and a public health school. ${ }^{22,23}$ However, to our knowledge, such programs are not common in pharmacy education.

Additionally, assessment of teaching abilities can be quite challenging with heavy reliance on student evaluation. ${ }^{24}$ Other options that have shown benefit include faculty peer evaluation and self-reflections. ${ }^{25-29}$ However, we are not aware of any published research comparing assessment methods and examining relationships between them.

Overall, there is limited literature on pharmacy student teaching programs, especially regarding mentoring students who have expressed an interest in academic careers. The analysis of our TA program presented in this paper contributes to understanding the value of this type of program and its potential impact on pharmacy students' self-confidence in teaching abilities and career interests. The study also attempted to fill the gap in literature on assessment methods for such a program through comparative analysis of 3 evaluation methods: student evaluations, faculty evaluations, and TA self-evaluations.

\section{METHODS}

Pharmaceutical Care Laboratories (PCL) at the UNC Eshelman School of Pharmacy is a series of courses taught over 5 semesters that cover topics of contemporary pharmacy practice using a small-group learning format. As part of this series, selected third-year (PY3) pharmacy students served as TAs for the 2 courses taught to firstyear PharmD students. A TA program has been in place at the school since the 1990s and has expanded over the years to include additional requirements. A study was conducted over 2 semesters (August 2014-April 2015) to assess the benefit of the program.

The TA program was available to PY3 students at both the main campus and the satellite campus. The competitive selection process was based on a written application, a curriculum vitae, and an interview. Once selected, the students agreed to serve as TAs for 2 consecutive semesters and were compensated on an hourly basis. The TA program involved 7 components: orientation, weekly small group facilitation and grading, commitment to student professionalism development, weekly TA meeting, creation of learning activities, writing teaching reflections, and development of teaching goals.

The program required the TAs to participate via video-conferencing technology in a 1-day summer orientation session held at the main campus. During this orientation, TAs were informed about the school's policies and procedures, participated in a teaching workshop, and completed the Pharmacists' Inventory of Learning Styles (PILS). ${ }^{30}$ The incorporation of the PILS assessment was designed to help TAs understand their dominant learning style as well as to acknowledge the variation in style among learners. TAs were encouraged to think about different learning preferences and, when appropriate, incorporate varied teaching methods to target each of these learning preferences.

Throughout the 2 semesters, TAs were responsible for facilitating small-group learning once weekly for a group of 6 to 8 students. Group membership was set at the beginning of each semester and remained consistent through the entire semester. Group membership was randomly assigned within 3 sections in which students enrolled through the course registrar. This consistency allowed both TAs and students to form lasting collegial relationships. The content of the weekly laboratory sessions varied from week-to-week, but were designed to be completed during a 4-hour laboratory period. Common topics included: top 200 drug review, calculations, compounding, professionalism, physical assessment, drug information, prescription verification, counseling, medication therapy management, aseptic technique, and student presentations. TAs were given detailed teaching instructions and answer keys for each activity. The teaching instructions were provided in the form of a weekly TA guide that included student learning objectives, directions for each activity, and an estimated timeline. Additionally, TAs were responsible for a select amount of grading including quizzes, homework assignments, and in-class activities. Clear grading instructions were provided on the activity keys and TAs had the opportunity to seek clarification from the instructor before assigning the final grades.

Another TA responsibility was a commitment to student professionalism development. This series of laboratories had a professionalism component with which both students and TAs were required to comply. Specifically, it involved arriving to laboratory on time, proper preparation, effective communication, demonstration of respect to classmates and faculty, appropriate contributions to the small group, use of good problem-solving skills, appropriate laboratory technique, and professional dress. For students, failure to adhere to any of the professionalism policies would result in loss of points from the final course grade. In addition to faculty members, TAs had the responsibility to uphold the policy and issue an infraction if students were not in compliance. For TAs, failure to adhere to the policies initially would result in a verbal warning. Although extremely rare, if the behavior continued, employment termination was a possibility. Furthermore, 


\section{American Journal of Pharmaceutical Education 2016; 80 (9) Article 149.}

TAs met with each student individually at the start, midpoint, and end of the semester to discuss professionalism and individualized student goals. This allowed TAs and students to form in-depth relationships with one another and for TAs to individualize instruction.

In addition to the weekly group facilitation and ongoing professionalism development, TAs also were required to attend a 1-hour weekly meeting with their faculty member via video conference. During the TA meetings, the faculty member debriefed the TAs regarding events occurring the previous week, including classroom activities and any grading questions that came up. The discussion focused on ways to improve teaching and troubleshoot any concerns. The second portion of the meeting was used to explain the expectations for the upcoming week and answer any logistical questions. Additionally, when time allowed, the TAs were presented with a hypothetical teaching situation to discuss. Topics for these hypothetical situations included: plagiarism, cheating, quiet students, constructive feedback, social encounters, inquisitive students, grading check-offs, and mixed learning preferences. These discussions were very fruitful with a lot of ideas proposed during each session. Although time was not available every week for these discussions, 10 topics were discussed throughout the year with approximately 10-20 minutes allotted for each discussion.

Finally, TAs were asked to develop one learning activity and write one teaching reflection each semester. Guidelines and examples were provided for both of these assignments. For the learning activity, TAs could reformat a current activity or identify a gap in the current course lesson plans and create a new laboratory activity. TAs submitted these learning activities to the instructor 1 week in advance for feedback, and then they implemented their proposed plan.

The teaching reflection was a short writing exercise in which TAs reflected on their experiences during the small group facilitation for a particular week. A series of proposed questions was provided to help guide this writing. The TAs submitted these teaching reflections to the instructor who reviewed them and provided written feedback to the TAs.

One final piece of the program was the development of teaching goals each semester. TAs were asked to write 1 teaching goal each semester and then reflect on the progress for this goal at the end of the semester. In line with the development of these teaching goals was the regular opportunity for faculty mentoring. Each semester the course coordinator devoted a large amount of time to mentoring the TAs. This occurred in a group format during the weekly TA meetings and individually when student concerns arose, when TAs created learning activ- ities, and when TAs wrote their teaching reflections. Communication with faculty members and mentorship were available for all TAs on a continuous basis.

\section{EVALUATION}

One of the goals of the program was to develop TAs confidence in teaching. The authors in collaboration with course faculty members developed a 10-item survey tool, the Teaching Abilities Survey (Appendix 1), to assess TA self-confidence in their teaching abilities. For each of the 10 items, TAs were asked to choose a numerical value on a scale of 0 to 100 to rate their confidence in their ability to perform specific teaching-related tasks ( 0 being not confident and 100 being very confident). Teaching assistants' interest in academia was assessed by asking TAs to rate their level of interest in pursuing an academic pharmacy career on a 5-point Likert scale (strongly disagree to strongly agree). The survey instrument was completed 3 times by all TAs: prior to the first semester (pre survey, August 2014), at the end of the first semester (midpoint survey, December 2014), and at the end of the second semester (post survey, April 2015). The survey instrument was distributed to TAs online via Qualtrics (Qualtrics LLC, Provo, UT).

Additionally, regular evaluation of TAs was conducted using a triangulation approach. Specifically, a faculty evaluation, student evaluations, and a self-evaluation were completed for each TA each semester. The faculty evaluation was completed once each semester and was based on observation of the TAs interactions with their students for a portion of 1 weekly laboratory session (approximately 2-4 hours). The faculty members completed a 3-page evaluation form (Appendix 2) which asked a series of questions on organization, preparation, rapport, credibility and control, active learning, and interaction. Each criterion was assessed as satisfactory, needs improvement, or not applicable. Additionally, both written and verbal feedback was provided on teaching strengths and opportunities for improvement. Seven faculty members were involved with TA evaluation. While only 2 of the 7 faculty members had formal training, all faculty members had been involved with TA evaluation in prior years.

The TAs received an evaluation from a different faculty member each semester to provide an alternative perspective. Although each TA was evaluated once each semester, there was not a set time for evaluations to be completed. Thus, some TA evaluations were conducted at the beginning of the semester, others in the middle of the semester, and the remaining evaluations towards the end of the semester. This was the method chosen because only a small number of faculty members completed these 


\section{American Journal of Pharmaceutical Education 2016; 80 (9) Article 149.}

evaluations and they needed to devote sufficient time to each TA evaluation. Additionally, these evaluations were a surprise visit so that TAs would not prepare differently.

Student evaluations were completed at the end of each semester. Students evaluations were optional and consisted of 8 questions with answers on a 5-point Likert scale (strongly disagree to strongly agree). Formal instructions and reminders for completion of these evaluations were sent out by the Office of Strategic Planning and Assessment. Finally, TAs completed a self-evaluation by responding to the same 8 questions to which the students responded at the end of each semester (Appendix 3).

The statistical analysis was done using SPSS for Windows, Version 22 (IBM, Armonk, NY). Because of the small sample size, nonparametric tests were used. Friedman's test was used to compare the pre-semester, midpoint, and post-semester scores from the Teaching Abilities Survey. Kruskal-Wallis H test was used to compare the 3 TA evaluation assessments with Wilcoxon signed rank test for post-hoc analysis. Spearman's rho was used for correlation analysis. Faculty evaluations were scored as follows: 1 point for satisfactory, 0 points for needs improvement, and those survey instruments that were not applicable were omitted. The total score was then converted to a percentage and multiplied by 5 to convert to a common scale. Student and TA self-evaluations were scored as follows: 1 point for strongly disagree, 2 points for disagree, 3 points for neither disagree nor agree, 4 points for agree, and 5 points for strongly agree. Average score was used in the analysis. The study was approved by the University of North Carolina Institutional Review Board.

\section{RESULTS}

Of the 60 applicants to the teaching assistant program during the 2014 recruitment season, 21 students were selected to serve as TAs ( 18 TAs on the main campus and 3 TAs on the satellite campus). All 21 TAs (100\%) agreed to participate in the study. Descriptive statistics are summarized in Table 1. The majority of the TAs were female $(71.5 \%)$, had a previous undergraduate degree $(81.0 \%)$, and had community pharmacy intern experience $(80.9 \%)$. Additionally, the majority $(61.9 \%)$ of TAs identified their PILS learning preference as assimilator. ${ }^{30}$

The analysis of the Teaching Abilities Survey pre-, midpoint, and post-study scores showed improvement in TA self-confidence in teaching abilities (Table 2). These changes were significant for all 10 abilities evaluated, with the overall score increasing from 80.7 to 91.4 $(p<0.001)$. Post-hoc analysis revealed variations in individual item scores changes. For 6 of the abilities (items 1 , $3-5,8$ and 9) there were significant increases in scores
Table 1. Demographics for Third-Year Doctor of Pharmacy Students Participating in a Teaching Assistant Program

\begin{tabular}{lc}
\hline Characteristic & Result \% \\
\hline Age, y Average (SD) & $24.9(3.09)$ \\
Female & 71.5 \\
Previous undergraduate degree & 81.0 \\
Previous teaching degree & 4.8 \\
Current or previous community & 80.9 \\
$\quad$ pharmacy intern & \\
Current or previous hospital & 9.5 \\
$\quad$ pharmacy intern & \\
PILS* Learning Preference: & \\
$\quad$ Assimilator & 61.9 \\
Converger & 19.0 \\
Accomodator & 4.8 \\
Diverger & 4.8 \\
Combination & 9.5 \\
\hline
\end{tabular}

*Austin Z. Development and validation of the pharmacists' inventory of learning styles (PILS). Am J Pharm Educ. 2004;68(2):Article 37

from pre to midpoint and again from midpoint to post, showing continued growth in the development of these areas. However, 2 of the abilities ("facilitate a small group" and "grade student work fairly") scores increased significantly by midpoint, with no additional significant change noted between the midpoint and post surveys. For the other 2 abilities ("provide students with constructive feedback" and "serve as an educator"), the change between pre and midpoint was not significant, but the overall scores increased. Although there was some fluctuation between pre, midpoint, and post surveys, the vast majority of TAs either strongly agreed (6 of 21) or agreed (12 of 21) that they had interest in pursuing academic pharmacy at the conclusion of the TA program (Figure 1).

During the study period of 2 semesters, a total of 42 faculty evaluations (21 each semester), 180 student evaluations (120 in the fall semester and 60 in the spring semester), and 42 TA-self evaluations (21 each semester) were completed. Regarding the optional student evaluations, the fall semester had a response rate of $75 \%$ with an average of 5.7 evaluations completed for each TA. However, the response rate for the spring semester was only $40 \%$, with an average of 2.9 evaluations for each TA. When comparing the 3 types of assessments (faculty, student, and TA self-evaluation), there was a significant difference between the scores from the 3 evaluations in both the fall semester $\left(\chi^{2}(2)=7.25, p=0.027\right)$ and the spring semester $\left(\chi^{2}(2)=16.9, p=<0.001\right)$. Post-hoc analysis showed TA self-evaluations were significantly lower than student evaluations in the fall semester $(Z=-2.91$, $p=0.004)$. Additionally in the spring semester, selfevaluations were significantly lower than both student 
American Journal of Pharmaceutical Education 2016; 80 (9) Article 149.

Table 2. Comparison of TA self-confidence from the Teaching Abilities Survey

\begin{tabular}{|c|c|c|c|c|}
\hline I feel confident in my ability to: & Pre Mean (SD) & Midpoint Mean (SD) & Post Mean (SD) & $P$ value* \\
\hline $\begin{array}{l}\text { 1. Communicate concepts effectively to a } \\
\text { group of students }\end{array}$ & $78.5(11.2)$ & $86.8(7.4)$ & $91.1(7.2)$ & $<0.001$ \\
\hline 2. Facilitate a small group discussion & $75.8(17.2)$ & $89.7(6.9)$ & $89.8(7.7)$ & $<0.001$ \\
\hline $\begin{array}{l}\text { 3. Create a motivating environment for pharmacy } \\
\text { students to participate in learning activities }\end{array}$ & $80.0(12.5)$ & $87.1(7.2)$ & $90.7(8.3)$ & 0.001 \\
\hline $\begin{array}{l}\text { 4. Adapt my teaching to accommodate the } \\
\text { diversity of students' learning preferences }\end{array}$ & $71.2(17.9)$ & $81.4(9.5)$ & $88.3(8.5)$ & $<0.001$ \\
\hline $\begin{array}{l}\text { 5. Design an effective learning exercise for } \\
\text { pharmacy students }\end{array}$ & $78.0(15.2)$ & $85.7(9.1)$ & $91.0(7.6)$ & $<0.001$ \\
\hline 6. Grade student work fairly & $87.8(12.9)$ & $92.1(8.4)$ & $94.4(8.0)$ & 0.003 \\
\hline 7. Provide students with constructive feedback & $82.7(11.2)$ & $86.1(11.1)$ & $90.6(8.1)$ & $<0.001$ \\
\hline $\begin{array}{l}\text { 8. Resolve student conflicts with confidence } \\
\text { and authority }\end{array}$ & $75.2(13.3)$ & 80.9 (11.9) & $86.8(9.0)$ & $<0.001$ \\
\hline $\begin{array}{l}\text { 9. Serve as an effective role model for } \\
\text { pharmacy students }\end{array}$ & $90.6(7.6)$ & $93.7(6.6)$ & $96.5(4.8)$ & $<0.001$ \\
\hline 10. Serve as an educator & $86.7(8.1)$ & $89.7(7.2)$ & $94.6(4.7)$ & $<0.001$ \\
\hline Overall Score & $80.7(9.9)$ & $87.3(6.9)$ & $91.4(5.6)$ & $<0.001$ \\
\hline
\end{tabular}

*Based on the Friedman's test

evaluations $(\mathrm{Z}=-2.56, p=0.011)$ and faculty evaluations $(\mathrm{Z}=-3.44, p=0.001)$. Further analysis showed no correlation between the scores on the 3 evaluation instruments in either fall or spring semester, nor were there any correlations between fall and spring evaluation scores given by faculty members or students. The TA self-evaluations, however, were highly correlated between the fall and spring semesters $\left(\mathrm{r}_{\mathrm{S}}=0.78, p=<0.001\right)$.

\section{DISCUSSION}

The PY3 TA program was successful in improving participants' teaching confidence as evidenced by consistent improvements in scores on the TA self-confidence in the Teaching Abilities Survey. Of note, the majority of scores increased significantly after only 1 semester; however, for all but 2 of the abilities, there was even further improvement after a second semester of teaching. Furthermore, 2 outcomes required 2 semesters to show a meaningful difference. The 2 abilities that did not improve further after the second semester may have required less time for the students to develop. Likewise, the 2 abilities that did not improve significantly by the end of the first semester but did improve significantly by the end of the second semester, may have require more time for the students to fully develop. This highlights the value of continued opportunities for structured teaching to refine teaching skills and build additional confidence.

In a previous study in which pharmacy students participated in 3 educational elective courses, the authors demonstrated increased knowledge and teaching skills, but only some of the results were statistically significant. ${ }^{16}$ We believe the overall success of our program was due to the rigorous TA responsibilities and the ongoing mentorship provided by PCL faculty members. Our program involved many components including weekly small-group facilitation, grading, weekly TA meetings,

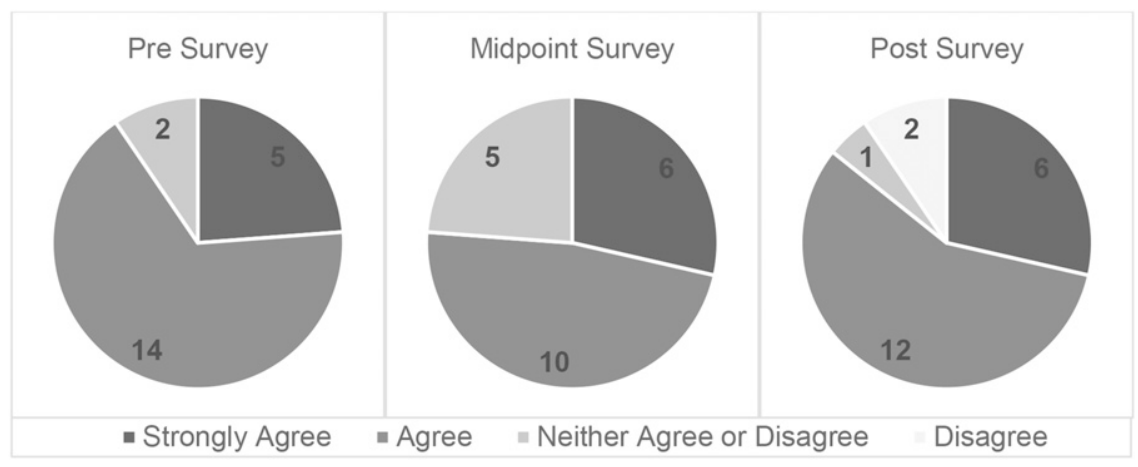

Figure 1. Number of Teaching Assistants Interested in Pursuing an Academic Career. 


\section{American Journal of Pharmaceutical Education 2016; 80 (9) Article 149.}

activity creation, and reflection writing. All of these activities probably helped the PY3 students increase their understanding of academic pharmacy and comfort with teaching students. This is in contrast to other TA or tutoring opportunities in which students often only are exposed to a portion of academia, such as administration work, test writing, or grading assistance. ${ }^{2}$ Additionally, faculty mentorship was present throughout the entire TA program, beginning the day of orientation when TAs were asked to set specific teaching goals for themselves. During faculty evaluations, faculty members provided detailed feedback using the faculty evaluation form and also gave verbal feedback on the specific TA teaching goals. Finally, discussion of teaching techniques and resolution of concerns were constantly encouraged during brief weekly encounters and scheduled weekly meetings. Overall, we believe the goals of this TA program were accomplished by creating opportunities for PY3 students to actually teach and learn from those experiences rather than just delivering content and grading papers.

In addition to the improvement in TA self-confidence, the fact that the majority of TAs continued to have an interest in pursuing a career in academia throughout the experience was a promising indicator of the program's success. As mentioned earlier, it is important for pharmacy schools to provide opportunities for students to explore academia and it appears that this program achieved that goal. In 2 other studies measuring student interest in academia after completing either an academic pharmacy elective or a series of 3 didactic electives, $40 \%$ and $86 \%$ of students, respectively, responded that they would consider academic pharmacy as a career. ${ }^{13,16}$ Therefore, our results of more than $85 \%$ expressing interest were similar to those of these previous studies and indicative of the program's success. There was a fluctuation of interest between the pre, midpoint, and post surveys with a decrease in interest occurring during the midpoint survey. Although we did not ask TAs to provide explanations on the survey instrument to gain an understanding of why there was a change in interest level, TAs often mentioned to faculty members that teaching was much different than they expected and often quite hard. Two students ultimately decided that they did not want to pursue a career in academia. We believe that deciding an academic career was not for them was equally important because these students could then invest their remaining time in the program preparing for other career paths. Faculty members emphasized to all TAs that every pharmacist is involved in teaching in some sense, whether teaching students, providing patient education, or consulting with other health care providers. Thus, they could apply lessons from their TA experience in any pharmacy career.
While our study found differences among 3 types of assessment tools (faculty, student, and TA self-evaluation), we did not find any correlation among these evaluation methods. We believe that this is likely because the 3 tools provided assessments from different perspectives (eg, a faculty member may have different expectations for each teaching criterion compared to a student). Moreover, although each evaluation total score was converted to common scale for analysis, there was substantial difference between student/TA and faculty evaluation forms in number of items, item type, and evaluation scale. The use of established forms for these assessments is one of the limitations of the study, precluding comparison of scores on specific items between the different assessment tools. In the future, investigators should consider using consistent evaluation tools to provide further guidance on the extent of this limitation. Additionally, the faculty evaluation technique varied on the satellite campus compared to the main campus. Because of the smaller faculty to TA ratio on the satellite campus, the faculty members were able to observe the TAs on a more regular basis. Thus, their observations about the TAs' performance were based on the entire semester as opposed to the 1-day observation period of TAs on the main campus. The changes in faculty assessors and student small group composition between the fall and spring semesters is the likely reason for lack of correlation between scores of the same assessment type between the 2 semesters. Also, there was a significantly lower response rate for the optional student evaluation in the spring semester compared to the fall semester. The authors believe that this is probably because of the strong emphasis that was placed on student evaluations by the course coordinator in the fall semester. Additionally, previous data from the Office of Strategic Planning and Assessment indicate that response rates for spring courses tend to be lower than fall courses. Taken together, the lack of correlation between different assessments highlights the importance of including a variety of evaluation tools and methods to provide the most comprehensive assessment and meaningful feedback to the TAs. This finding is consistent with a previous survey of colleges and schools of pharmacy in which it was shown that teaching evaluation methods expanded from 1996 to 2007 , with $66 \%$ of schools using evaluation by peers and $49 \%$ using self-appraisal in addition to student evaluations. ${ }^{24}$

Another limitation of this study was the small sample size. Although all TAs from the 2014-2015 cohort agreed to participate, the overall small number of participants limits the power of statistical analysis and may have contributed to the lack of correlation found among the various assessment tools. Despite this limitation, we believe this study provides compelling evidence regarding the TA 


\section{American Journal of Pharmaceutical Education 2016; 80 (9) Article 149.}

program's capability to improve self-confidence in teaching abilities and expose students to the reality of a career in academia. Our hope is that similar TA programs could be implemented at our institution and other professional schools. Additionally, we would encourage the use of multiple assessment methods for TAs and faculty members as each tool and evaluator may provide varying types of valuable feedback. A future area that we would like to study is to evaluate whether improvements in TA self-confidence correlate with improvements in quality of teaching.

\section{CONCLUSION}

The TA program at UNC Eshelman School of Pharmacy was effective as an educational experience to improve confidence in teaching abilities for PY3 student TAs. Similar programs could be developed at other pharmacy or health professional schools. Additionally, the lack of correlation among assessment methods highlights the importance of various forms of feedback, such as a triangulation of assessments, for both TAs and faculty members.

\section{ACKNOWLEDGMENTS}

We would like to thank the other 2014-2015 PCL team members, including Heidi Anksorus, Daniel Forrister, Amanda Johnson, Amanda Savage, and Bob Shrewsbury, for their efforts in mentoring the TAs throughout the entire two semesters.

\section{REFERENCES}

1. Wanat MA, Garey KW. A blueprint of transitioning pharmacy residents into successful clinical faculty members in colleges and schools of pharmacy. Am J Pharm Educ. 2013;77(9):Article 200. 2. Brooks AD. Considering academic pharmacy as a career: opportunities and resources for students, residents, and fellows. Curr Pharm Teach Learn. 2009;1(1):2-9.

3. Kirdahy K, Turner S, Williams J. Description of an academic teaching rotation for postgraduate year 1 pharmacy residents. Am J Health-Syst Pharm. 2012;69(3):228-231.

4. Ostroff J, Anksorus H. An academia rotation during a postgraduate year 2 residency. Am J Health-Syst Pharm. 2014;71 (12):998-999.

5. Slazak EM, Zurick GM. Practice-based learning experience to develop residents as clinical faculty members. Am J Health-Syst Pharm. 2009;66(13):1224-1227.

6. McNatty D, Cox CD, Seifert CF. Assessment of teaching experiences completed during accredited pharmacy residency programs. Am J Pharm Educ. 2007;71(5):Article 88.

7. Manasco KB, Bradley AM, Gomez TA. Survey of learning opportunities in academia for pharmacy residents. Am J Health-Syst Pharm. 2012;69(16):1410-1414.

8. Romanelli F, Smith KM, Brandt BF. Teaching residents how to teach: a scholarship of teaching and learning certificate program (STLC) for pharmacy residents. Am J Pharm Educ. 2005;69(2): Article 20.
9. Castellani V, Haber SL, Ellis SC. Evaluation of a teaching certificate program for pharmacy residents. Am J Health-Syst Pharm. 2003:60(10):1037-1041.

10. Medina MS, Herring HR. An advanced teaching certificate program for postgraduate year 2 residents. Am J Health-Syst Pharm. 2011;68(23):2284-2286.

11. Nappi JM. An academician preparation program for pharmacy residents. Am J Pharm Educ. 2013;77(5):Article 101.

12. Gonzalvo JD, Ramsey DC, Sheehan AH, Sprunger TL. Redesign of a statewide teaching certificate program for pharmacy residents. Am J Pharm Educ. 2013;77(4):Article 79.

13. Baia P, Strang A. An elective course to promote academic pharmacy as a career. Am J Pharm Educ. 2012;76(2):Article30. 14. Sylvia LM. An advanced pharmacy practice experience in academia. Am J Pharm Educ. 2006;77(5):Article 97.

15. Roche VF, Limpach AL. A collaborative and reflective academic advanced pharmacy practice experience. Am J Pharm Educ. 2011;75 (6):Article 120.

16. Poirier TI, Santanello C. Impact of a pharmacy education concentration on students' teaching knowledge and attitudes. Am J Pharm Educ. 2010;74(2):Article 23.

17. Santee J, Garavalia L. Peer tutoring programs in health professional schools. Am J Pharm Educ. 2006;70(3):Article 70.

18. Goode VM, Horvath C, Jasinski D. Implementation of a teaching assistant program in graduate nursing education. Nurse Educ. 2013;38(5):188-190.

19. Romm I, Gordon-Messer S, Kosinski-Collins M. Educating young educators: a pedagogical internship for undergraduate teaching assistants. CBE Life Sci Educ. 2010;9(2):80-86.

20. Nimmo A, Mitchell GS, Echeto L, Ojha AK. Effect of dental students as instructors on preclinical performance in prosthodontics. $J$ Dent Educ. 2008;72(12):1488-1492.

21. Machen RR, Hammer D, Odegard P. Elective course in nutrition taught by a pharmacy student. Am J Pharm Educ. 2007;71(4):Article 65. 22. Hicks JL, Hendrickson WD, Partida MN, Rugh JD, Littlefield JH, Jacks ME. Career transition and dental school faculty development program. Tex Dent J. 2013;130(11):1115-1122. 23. Koblinsky SA, Hrapczynski KM, Clark JE. Preparing future faculty and professionals for public health careers. Am J Public Health. 2015;105(Suppl 1):S125-S131.

24. Barnett CW, Matthews HW. Teaching evaluation practices in colleges and schools of pharmacy. Am J Pharm Educ. 2009;73(6): Article 103.

25. Wellein MG, Ragucci KR, Lapointe M. Instructional design and assessment. Am J Pharm Educ. 2209;73(5):Article 79.

26. Trujillo JM, DiVall MV, Barr J, et al. Development of a peer teaching-assessment program and a peer observation and evaluation tool. Am J Pharm Educ. 2008;72(6):Article 147.

27. Schultz KK, Latif D. The planning and implementation of a faculty peer review teaching project. Am J Pharm Educ. 2006;70 (2): Article 32.

28. Hansen LB, McCollum M, Paulsen SM, et al. Evaluation of an evidence-based peer teaching assessment program. Am J Pharm Educ. 2007;71(3):Article 45.

29. DiVall M, Barr J, Gonyeau M, et al. Follow-up assessment of a faculty peer observation and evaluative program. Am J Pharm Educ. 2012;76(4):Article 61.

30. Austin Z. Development and validation of the pharmacists' inventory of learning styles (PILS). Am J Pharm Educ. 2004;68(2): Article 37. 
American Journal of Pharmaceutical Education 2016; 80 (9) Article 149.

Appendix 1. Teaching Abilities Survey

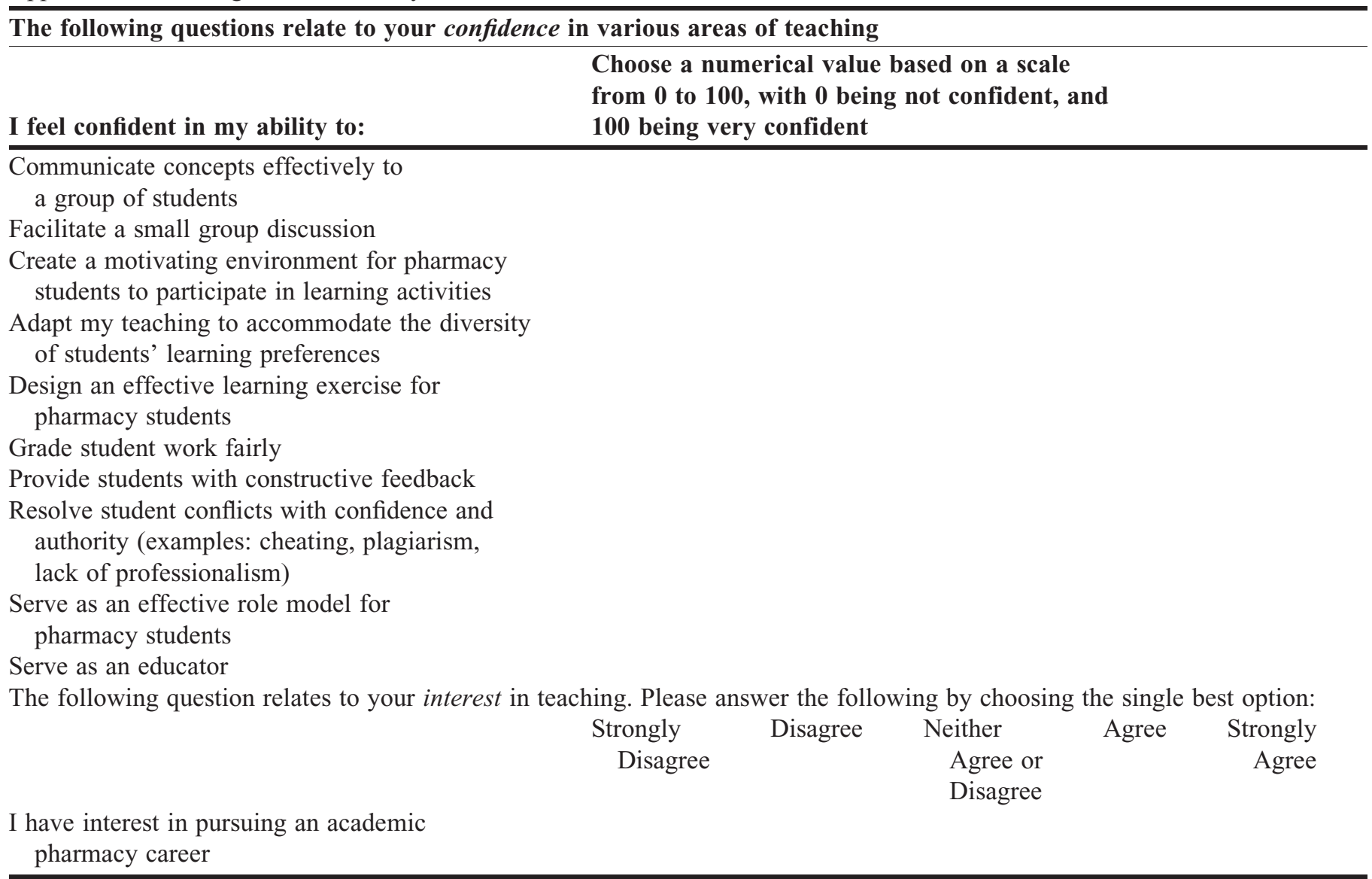

Appendix 2. Faculty Evaluation Form

Teaching Assistant Evaluation Form

UNC Eshelman School of Pharmacy

Semester

Teaching Assistant Name:

Course Session Observed:

Date and Time:

Number of Students:

Observer:

$\mathrm{S}=$ Satisfactory NI=Needs Improvement N/A=Not Applicable

\begin{tabular}{lllll}
\hline Organization & S NI & N/A & Comments \\
\hline
\end{tabular}

Begins class on time in an orderly fashion

Previews lecture/discussion content

States the goal/objectives for the session

Reviews prior class material as set-up

Provides internal summaries and transitions

Does not digress often from the main topic

Summarizes main points at the end of session 
American Journal of Pharmaceutical Education 2016; 80 (9) Article 149.

(Continued)

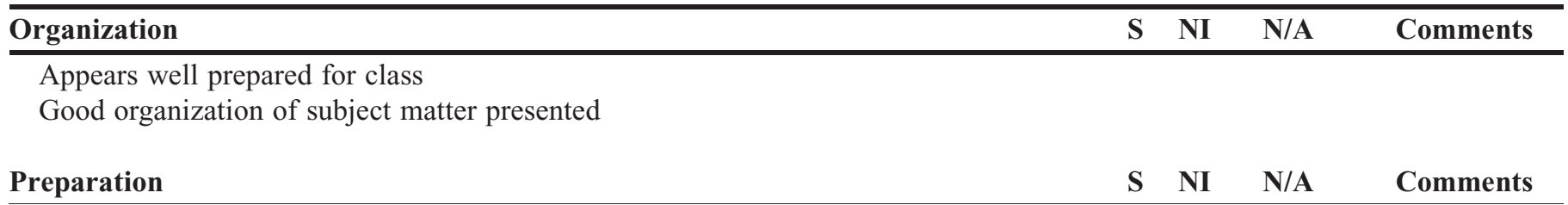

Incorporates various instructional supports (ex: slides, films, diagrams)

Uses instructional support effectively

Responds to changes in student attentiveness

Visuals are large and legible

Speech fillers (for example "ok, ahm") are not distracting

Speaks audibly and clearly

Uses gestures to enhance meaning

Communicates enthusiasm for the content

Use of humor is positive and appropriate

Presentation style facilitates note taking

Speech is neither too formal nor too casual

Establishes/maintains eye contact with class

Talks to the class, not the board or computer

Varies the pace to keep students alert

Selects appropriate teaching methods (e.g., discussion, role play, demonstration, etc.)

\begin{tabular}{lllll} 
Rapport & S NI N/A & Comments \\
\hline
\end{tabular}

Praises students for contributions that deserve commendation

Solicits student feedback

Requires student thought and participation

Responds constructively to student opinions

Treats class members equitably

Listens carefully to student comments

Recognizes when students do not understand

Encourages mutual respect between students

Credibility and Control

S NI N/A Comments

Responds to distractions effectively

Demonstrates content-competence

Responds confidently to student inquiries for additional information

Uses authority in classroom to create an environment conducive to learning

Speaks about content with confidence and authority

Is able to admit error and/or insufficient knowledge

Respects constructive criticism

\section{Active Learning}

S

Clearly explains directions or procedures

Clearly explains the goal of the activity

Has materials and equipment necessary to complete the activity readily available

Allows opportunity for individual expression

Provides individual constructive feedback

Careful safety supervision is obvious

Allows sufficient time for completion

Provides sufficient demonstrations

Demonstrations are clearly visible 
American Journal of Pharmaceutical Education 2016; 80 (9) Article 149.

(Continued)

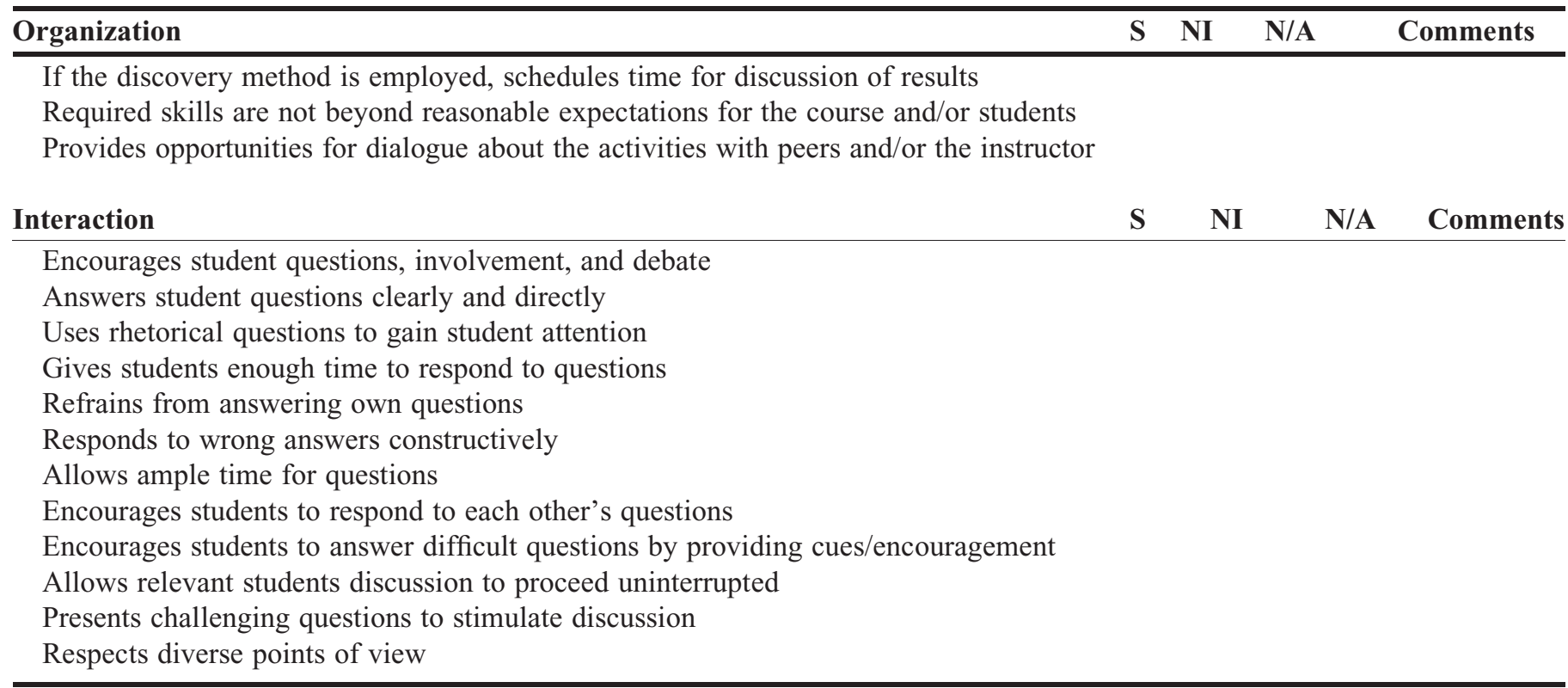

Summary Comments

(Reviewer is encouraged to attach additional comments if necessary)

What does the teaching assistant do best?

What requires the teaching assistant's attention?

Suggestions for enhancement of teaching:

PCL Faculty Member:

Date:

PCL Director: Date:

Teaching Assistant: Date:

Appendix 3. Student and TA Self-evaluation Form

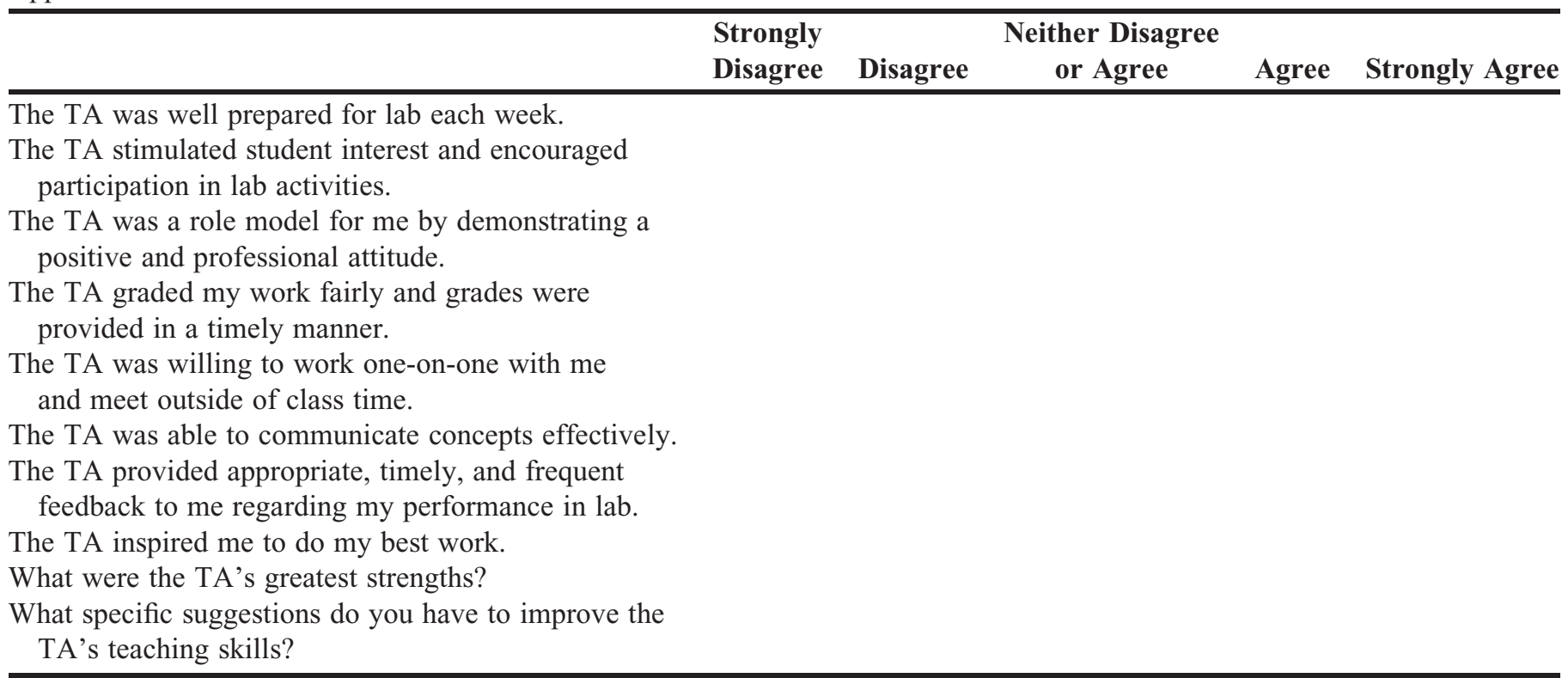

